\title{
Role of the granuloma in recurrent Crohn's disease
}

\author{
R. E. GLASS AND W. N. W. BAKER
}

From the Gordon Hospital, London

SUMMARY The clinical significance of sarcoid-like granulomata in recurrent Crohn's disease has been investigated in 90 patients. The recurrence rate for non-granulomatous disease was double that of granulomatous disease. In granulomatous disease, involvement of the mesenteric lymph nodes did not affect the recurrence rate. This suggests that sarcoid-like granulomata reflect the patients' immune response and support the view that excision of the lymphatic drainage en bloc with affected bowel is not indicated.

Crohn's disease has a reputation for recurrence despite the surgical excision of all macroscopically diseased bowel.

Antonious et al. (1960) stated that no satisfactory clinicopathological correlation had ever been established between various microscopic features and the behaviour of the disease. Morson (1968) suggested that the spread of sarcoid-like granulomata to lymph nodes would prove significant, and it has been the practice of some surgeons to remove the lymphatic drainage en bloc with the affected bowel as for malignant disease.

The aim of this review was to investigate the relationship between the presence of sarcoid-like granulomata in the bowel and associated mesenteric lymph nodes, and the subsequent course of the disease.

\section{Methods}

All patients who had undergone surgery for Crohn's disease at the Gordon Hospital between the years 1950-70 were reviewed. Those patients fulfilling the following criteria were included in the review:

1. Primary surgical excision performed at this hospital.

2. Documented histological evidence, according to the criteria laid down by Morson (1964) of Crohn's disease at the time of resection.

3. Histological examination of both bowel and its associated mesenteric lymph nodes available.

4. Evidence of recurrence provided by (a) further operation and histology (88 patients); (b) radiological evidence (two patients). Symptomatic evidence of recurrence alone, was not accepted.

Received for publication 28 October 1975
5. Full follow-up for a minimum of five years after operation.

\section{Results}

Ninety patients fulfilled the above criteria. During the follow-up period 13 patients died, but in all these patients recurrence occurred before death and they were included in the review; in only six patients was death directly related to the Crohn's disease.

\section{GROUPING OF PATIENTS}

There were 45 males and 45 female patients who were subdivided into the following groups on histological evidence:

Group $A$ Seventeen patients $(18 \cdot 8 \%), 11$ females and six males, who showed sarcoid-like granulomata within the bowel wall and associated lymph nodes.

Group B Forty-three patients (47.7\%), 18 females and 25 males, who showed local bowel wall sarcoidlike granulomata but none in associated mesenteric lymph nodes.

Group C Thirty patients (33.3\%), 16 females and 14 males, who showed no sarcoid-like granulomata either in the bowel wall or associated mesenteric lymph nodes.

The follow-up period had a mean of 9.4 years with a range of five to 22 years.

Recurrence occurred in 38 patients $(42.0 \%)$, but the recurrence rate was different in group $C$ compared with groups $\mathbf{A}$ and $\mathbf{B}$. The results are given in Table 1 and show that the recurrence in the nongranulomatous patients (group C) was almost twice that of the patients showing granulomata in their 


\begin{tabular}{llll}
\hline Group & No. & Recurred & $\%$ \\
\hline (a) Granulomata in bowel & 17 & 6 & 35 \\
and nodes & & & \\
(b) Granulomata in bowel & 43 & 14 & 33.5 \\
(c) Noll only & 30 & 18 & 60 \\
\hline
\end{tabular}

Table 1 Recurrence rate

initial operation specimens (groups A and B). This is statistically significant $P<0.025$.

Granulomatous patients (groups A and B) and non-granulomatous patients (group $C$ ) were further investigated to see if they differed in other respects.

\section{SEX INCIDENCE}

Sex incidence was equal. Recurrence in the granulomatous patients occurred in 10 males and 10 females. Recurrence in the non-granulomatous patients occurred in nine males and nine females.

\section{AGE AT PRESENTATION}

There was no difference between granulomatous and non-granulomatous patients. The average age at onset for granulomatous patients was 37 years, with a range of 11-79 years. The average age at onset for non-granulomatous patients was 35 years with a range of 18-78 years.

\section{LENGTH OF HISTORY BEFORE OPERATION}

There was no significant difference between granulomatous and non-granulomatous patients in the preoperative duration of disease symptoms.

DISEASE SITE (Table 2)

Table 2 shows the site of disease as a percentage of the patients with granulomatous and non-granulomatous disease. Of the total number of patients 60 had disease of the colon and rectum; 14 patients had small bowel disease only; and 16 patients had both small and large bowel disease.

There was no statistical difference between granulomatous and non-granulomatous patients with respect to the site of disease.

\begin{tabular}{llll}
\hline & $\begin{array}{l}\text { Colon and } \\
\text { rectum } \\
(\%)\end{array}$ & $\begin{array}{l}\text { Small } \\
\text { bowel } \\
(\%)\end{array}$ & $\begin{array}{l}\text { Small and } \\
\text { large bowel } \\
(\%)\end{array}$ \\
\hline $\begin{array}{l}\text { Granulomatous } \\
\text { patients }\end{array}$ & 70 & 13.9 & 16.1 \\
$\begin{array}{l}\text { Non-granulomatous } \\
\text { patients }\end{array}$ & 64 & 16 & 20 \\
\hline
\end{tabular}

Table 2 Disease site in granulomatous and non-granulomatous patients

\section{PATTERN OF RECURRENCE}

In both granulomatous patients and non-granulomatous patients, the majority of recurrences occurred within the first five years of their first operation. Isolated recurrences occurred up to 11 years after operation (Fig.). Average age at recurrence was 25 years for granulomatous patients, with a range of 19-60 years. Average age at recurrence was 32 years for non-granulomatous patients, with a range of $14-83$ years.

\section{HISTOLOGICAL CHANGES AT RECURRENCE}

Patients who showed sarcoid-like granulomata at primary excision retained this histological characteristic in subsequent pathological material.

In the 18 patients with no sarcoid-like granulomata at primary excision, nine patients subsequently demonstrated granulomata in their recurrent disease specimens.

TYPE OF OPERATION PERFORMED

Table 3 shows the type of operation performed as a percentage of granulomatous and non-granulomatous patients. There is no statistical difference in type of operation performed between the two groups of patients.

\section{FULMINATING DISEASE}

Seventeen patients underwent total colectomy and ileorectal anastomosis for fulminating disease. Of these, nine patients showed sarcoid-like granulomata and eight patients showed no granulomata.

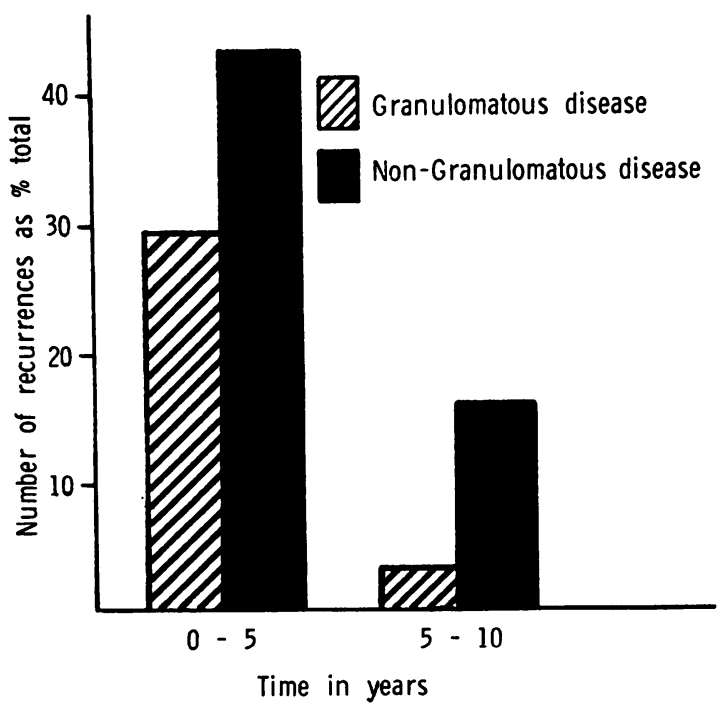

Figure Percentage recurrence rate for 'granulomatous' and 'non-granulomatous' Crohn's disease. 


\begin{tabular}{lllll}
\hline & $\begin{array}{l}\text { Total } \\
\text { colectomy }\end{array}$ & $\begin{array}{l}\text { R. colon } \\
\text { resection }\end{array}$ & $\begin{array}{l}\text { L.colon } \\
\text { resection }\end{array}$ & $\begin{array}{l}\text { Small } \\
\text { Intestine } \\
\text { only } \\
(\%)\end{array}$ \\
\hline$(\%)$ & $(\%)$ & $(\%)$ \\
\hline $\begin{array}{l}\text { Granulomatous } \\
\text { patients }\end{array}$ & 46.6 & 30 & 18.4 & 5 \\
$\begin{array}{c}\text { Non-granulomatous } \\
\text { patients }\end{array}$ & 46.6 & 26.7 & 16.7 & 10 \\
\hline
\end{tabular}

Table 3 Type of operation performed in patients with granulomatous and non-granulomatous disease

\section{Discussion}

This investigation reviews the clinical significance of sarcoid-like granulomata in Crohn's disease related to recurrence.

The series was selected on the availability of patients to fulfil the criteria stated above. The Gordon Hospital treats a higher proportion of colorectal inflammatory disease than the average general hospital and $86 \%$ of the patients in this series had large bowel involvement.

Morson (1964) stated that the absence of sarcoidlike granulomata did not rule out the diagnosis of Crohn's disease and emphasized other equally important histological criteria. These criteria were used to confirm the diagnosis of Crohn's disease in this investigation (Lockhart-Mummery and Morson, 1964).

The number of sarcoid-like granulomata found in a specimen is proportional to the diligence of the search (Warren and Summers, 1954). It is probable that some granulomata were missed, especially in the mesenteric lymph nodes. However, as the granulomatous patients appeared to behave as one group, the significance of 'missed' granulomata in lymph nodes will be diminished.

Although this series was selective, the incidence and pattern of recurrence was similar to other larger and more representative studies. The overall recurrence rate was $42 \%$ and both non-granulomatous and granulomatous patients showed the biphasic pattern of early and late recurrence described by De Dombal et al. (1971).

This investigation shows that granulomatous and non-granulomatous patients did not differ other than by the increased recurrence rate in nongranulomatous disease.

The presence of sarcoid-like granulomata within a specimen at primary excision appears to offer a better prognosis for the patient. Of the 18 patients who showed no sarcoid-like granulomata at primary resection, only nine maintained this characteristic at recurrence. The other nine patients demonstrated granulomata in the second or third excision specimens, suggesting that the disease process was uniform, and perhaps reflecting the late development of an immune response. Certainly there is no evidence from this investigation to support the view that affected mesenteric lymph nodes should be removed at operation.

The authors wish to express their gratitude to the surgeons of the Gordon Hospital, and to Mr S. O. Aylett in particular, for permission to study patients under their care.

\section{References}

Antonius, J. I., Gump, F. E., Lattes, R., and Lepore, M. (1960). A study of certain microscopic features in regional enteritis, and their possible prognostic significance. Gastroenterology, 38, 889-905.

De Dombal, F. T., Burton, I., and Goligher, J. C. (1971). Recurrence of Crohn's disease after primary excisional surgery. Gut, 12, 519-527.

Lockhart-Mummery, H. E., and Morson, B. C. (1964). Crohn's disease of the large intestine. Gut, 5, 493-509.

Morson, B. C. (1968). Histopathology of Crohn's disease. Proceedings of the Royal Society of Medicine, 61, 79-81.

Warren, S., and Summers, S. C. (1954). Pathology of regional ileitis and ulcerative colitis. Journal of the American Medical Association, 154, 189-193. 